\title{
Nghiên cứu nhu cầu đào tạo Cử nhân tâm lý chuyên ngành Tâm lý lâm sàng cho các cơ sở y tế
}

\author{
Phạm Trung Kiên ${ }^{1, *}$, Trần Thu Hương ${ }^{2}$ \\ ${ }^{I}$ Khoa Y Dược, Đại học Quốc gia Hà Nội, 144 Xuân Thủy, Cầu Giấy, Hà Nội, Việt Nam \\ ${ }^{2}$ Truờng Đại học Khoa học Xã hội và Nhân văn, Đại học Quốc gia Hà Nội, \\ 336 Nguyễn Trãi, Thanh Xuân, Hà Nội, Việt Nam \\ Nhận ngày 10 tháng 2 năm 2017 \\ Chỉnh sửa ngày 20 tháng 4 năm 2017; Chấp nhận đăng ngày 14 tháng 6 năm 2017
}

\begin{abstract}
Tóm tắt: Nghiên cứu khó khăn tâm lý và nhu cầu chăm sóc tâm lý của bệnh nhân và người thân tại các bệnh viện làm cơ sở xác định nhu cầu đào tạo và sử dụng đội ngũ chuyên gia chăm sóc tâm lý cho bệnh nhân. Kết quả: $32,5 \%$ bệnh nhân tại bệnh viện có khó khăn tâm lý; Tỉ lệ bệnh nhân có nhu cầu chia sẻ với nhân viên y tế là $42,0 \%$; Có $41,0 \%$ bệnh nhân có nhu cầu được chăm sóc toàn diện; $51,5 \%$ người thân của bệnh nhân thấy cần có nhân viên y tế chăm sóc bệnh nhân; Tỉ lệ nhân viên y tế quan tâm đến chăm sóc tâm lý cho bệnh nhân là $62,7 \%$ nhưng kỹ năng chủ yếu là giải thích bệnh và an ủi động viên. Lãnh đạo quản lý các bệnh viện thấy rất cần có đội ngũ chuyên gia được đào tạo chính quy, chuyên nghiệp đề chăm sóc tâm lý cho bệnh nhân tại bệnh viện, tốt nhất là các Cử nhân Tâm lý học lâm sàng.
\end{abstract}

Tù̀ khóa: Khó khăn tâm lý; Tâm lý bệnh nhân; Tâm lý học lâm sàng.

\section{1. Đặt vấn đề}

"Sức khỏe là một tình trang hoàn toàn sảng khoái về thể chất, tâm thần và xã hội, chư không phải chỉ là không có bệnh hay tật" [1], khi mắc bệnh không chỉ thể chất bị ảnh hưởng mà tinh thần cũng bị tác động rất lớn. Do vậy, khi điều trị bệnh ngoài việc can thiệp đến thể chất cần phải chăm sóc tinh thần cho bệnh nhân. Tổ chức Y tế Thế giới (TCYTTG) chỉ rõ, việc điều trị bệnh đạt hiệu quả tốt hơn nếu kết hợp cung cấp dịch vụ chăm sóc tâm lý tốt với việc sử dụng các loại thuốc chữa bệnh [2]. Tuy nhiên, ở các nước thu nhập thấp (trong đó có Việt Nam), bệnh nhân tại các bệnh viện thường chỉ được chăm sóc về thể chất mà ít được chăm

\footnotetext{
* Tác giả liên hệ. ĐT.: 84-913509141.

Email: ykkien@gmail.com

https://doi.org/10.25073/2588-1132/vnumps.4063
}

sóc tâm lý nên kết quả điều trị hạn chế [3]. Năm 2008, TCYTTG triển khai Chương trình trợ giúp các nước tăng cường dịch vụ chăm sóc tâm lý và quản lý những rối loạn tâm lý cho bệnh nhân [4]. Tại Việt Nam, Bộ Y tế Việt Nam có chỉ thị tăng cường công tác chăm sóc toàn diện bệnh nhân tại các bệnh viện, nhưng nội dung chăm sóc tinh thần cho người bệnh cũng chưa được chú trọng [5]. Năm 2011, Bộ Y tế đã xây dựng đề án Phát triển nghề Công tác xã hội trong ngành Y tế giai đoạn 2011-2020 $0^{[6]}$ để giải quyết vấn đề chăm sóc bệnh nhân tại các bệnh viện. Tuy nhiên, đội ngũ này không có đủ kiến thức về y học cũng như thiếu kỹ năng cần thiết để chăm sóc tâm lý cho bệnh nhân.

Vậy ai là người đảm trách tốt nhất việc chăm sóc tâm lý cho bệnh nhân tại bệnh viện? Tại các nước phát triển, công việc chăm sóc tinh thần và tâm lý cho bệnh nhân tại các bệnh 
viện rất được quan tâm. Mỗi đơn vị điều trị đều có các chuyên gia trợ giúp tâm lý cho người bệnh, họ thường là các nhà tâm lý học lâm sàng, đây là những chuyên gia quan tâm chăm sóc tâm lý liên quan đến bệnh tật và trợ giúp người bệnh các phương thức ứng phó với những tác nhân gây stress mà họ gặp phải. Tuy nhiên, tại Việt Nam Tâm lý học lâm sàng là một lĩnh vực còn hết sức mới mẻ, mới bắt đầu được xây dựng và đưa vào giảng dạy trong trường đại học từ cuối những năm 90 của thế kỷ $\mathrm{XX}$ tại Khoa Tâm lý học, Trường Đại học Khoa học Xã hội và Nhân văn, Đại học Quốc gia Hà Nội (ĐHQGHN). Do vậy, cho đến nay đội ngũ chuyên gia Tâm lý học lâm sàng làm việc tại các cơ sở y tế hầu như chưa có, nhưng có cần đào tạo hay không và sau khi đào tạo có được sử dụng hay không vẫn là câu hỏi cần có lời giải từ các nhà hoạch định chính sách

Những lý do trên đã thúc đẩy chúng tôi tiến hành nghiên cứu những khó khăn tâm lý của bệnh nhân, nhu cầu được chăm sóc tâm lý, thực trạng công tác chăm sóc tâm lý cho bệnh nhân và người thân, nghiên cứu nhu cầu sử dụng cán bộ chăm sóc tâm lý tại các bệnh viện, với mục tiêu đề xuất nhu cầu đào tạo chuyên gia Tâm lý lâm sàng cho các cơ sở y tế trong bối cảnh hội nhập quốc tế của Việt Nam hiện nay. Trên phương diện chính sách xã hội, chúng tôi muốn đề xuất vị trí việc làm cho nhân viên chăm sóc tinh thần cho bệnh nhân tại bệnh viện, những Chuyên gia Tâm lý lâm sàng có đủ kiến thức, kỹ năng cả về y học lẫn tâm lý, cả về lý thuyết lẫn thực hành. Đây là một vấn đề rất cấp thiết, có ý nghĩa nhân văn trong nâng cao chất lượng điều trị toàn diện cho bệnh nhân tại các cơ sở y tế.

\section{Mục tiêu}

2.1. Xác định nhu cầu chăm sóc tâm lý của bệnh nhân và nguời thân.

2.2. Đánh giá thực trạng và nhu cầu sủ dụng cán bộ tâm lý tại các co sơ y tế làm co sở xây dưng chuoong trình đào tạo củ nhân tâm lý chuyên ngành tâm lý lâm sàng cho cơ sởy tế.

\section{Phương pháp nghiên cứu}

\subsection{Phương pháp nghiên cứu tài liệu}

Tổng hợp, phân tích các công trình nghiên cứu, tài liệu trong và ngoài nước về nhu cầu, tâm lý bệnh nhân, nhu cầu chăm sóc tâm lý của người bệnh, các hoạt động chăm sóc tâm lý bệnh nhân tại các bệnh viện để xây dựng cơ sở lý luận của đề tài nghiên cứu. Nghiên cứu tài liệu về tâm lý lâm sàng, tình hình và các mô hình đào tạo tâm lý lâm sàng trên Thế giới, đề xuất mô hình đào tạo tâm lý học lâm sàng tại Việt Nam.

3.2. Phuoong pháp điều tra tại bệnh viện bằng bộ câu hỏi bán cấu trúc

- Đối tượng nghiên cứu:

Thực trạng và nhu cầu chăm sóc tâm lý cho bệnh nhân tại các bệnh viện.

- Khách thể nghiên cứu:

+ Bệnh nhân và người thân của bệnh nhân mắc các bệnh cấp tính, mạn tính và ác tính đang điều trị nội trú tại các bệnh viện.

+ Nhân viên y tế trực tiếp chăm sóc bệnh nhân tại các bệnh viện.

- Địa điểm nghiên cứu: Bệnh viện Đa khoa tỉnh Cao Bằng, Bệnh viện Đa khoa trung ương Thái Nguyên, Bệnh viện Sản Nhi Bắc Giang,

- Thời gian nghiên cứu: từ tháng 10 năm 2012 đến hết tháng 12 năm 2013.

- Nội dung nghiên cứu: phỏng vấn bệnh nhân; người thân của bệnh nhân; nhân viên y tế.

+ Cỡ mẫu nghiên cứu: nghiên cứu trên 400 bệnh nhân, 320 người thân của bệnh nhân.

+ Biến số nghiên cứu: các biến số chung (tuổi, nghề nghiệp...), chẩn đoán bệnh, thời gian mắc bệnh, thời gian nằm viện, khó khăn tâm lý, cách ứng phó, thời gian công tác...

+ Thu thập số liệu: nhóm nghiên cứu phỏng vấn trực tiếp khách thể nghiên cứu bằng bộ câu hỏi bán cấu trúc.

\subsection{Phỏng vấn sâu cán bộ quản lý}

- Đối tượng nghiên cứu: nhu cầu sử dụng nhân viên chăm sóc tâm lý cho bệnh nhân tại bệnh viện. 
- Khách thể nghiên cứu: cán bộ lãnh đạo của các bệnh viện (Ban Giám đốc, Ban chủ nhiệm các khoa lâm sàng).

Nội dung nghiên cứu: nghiên cứu định tính, tổ chức thảo luận nhóm nhỏ, phỏng vấn sâu khách thể nghiên cứu theo câu hỏi.

\subsection{Phương pháp thống kê toán học}

Sử dụng phần mềm SPSS 16.0 để xử lý các test thống kê.

\section{Kết quả nghiên cứu và bàn luận}

Để đánh giá những khó khăn tâm lý và nhu cầu chăm sóc tâm lý của bệnh nhân, chúng tôi tiến hành nghiên cứu trên những bệnh nhân đang điều trị nội trú tại một số bệnh viện.

Kết quả trong 400 bệnh nhân có 130 bệnh nhân có khó khăn về tâm lý, chiếm tỉ lệ 32,5\%. Chúng tôi thấy tỉ lệ có khó khăn tâm lý của nhóm bệnh cấp tính và mạn tính không có sự khác biệt $(\mathrm{p}>0,05)$ (Bảng 1$)$. Tuy nhiên, tỉ lệ bệnh nhân ở nhóm bệnh ác tính có khó khăn tâm lý cao hơn có ý nghĩa so với nhóm bệnh nhân cấp tính và mạn tính $(\mathrm{p}<0,05)$.

Phân tích trong số 130 bệnh nhân có khó khăn tâm lý, chúng tôi thấy lo lắng là biểu hiện có tỉ lệ cao nhất $(69,3 \%)$, nhưng tỉ lệ lo lắng và sợ hãi bệnh nhân của nhóm bệnh nhân mạn tính và ác tính không có sự khác biệt $(\mathrm{p}>0,05)$ (Bảng 2). Tỉ lệ lo lắng của nhóm bệnh nhân cấp tính thấp hơn so với hai nhóm bệnh mạn tính và ác tính, nhưng tỉ lệ có biểu hiện sợ hãi của nhóm bệnh cấp tính cao hơn so với nhóm bệnh mạn tính $(\mathrm{p}<0,05)$, điều này có thể lý giải do bệnh nhân mắc bệnh mạn tính họ đã quen với các triệu chứng bệnh của mình sau một thời gian dài chữa trị nên họ đã có những ứng phó tốt hơn. Chúng tôi thấy có một số ít bệnh nhân mắc bệnh mạn tính và ác tính bi quan chán nản và có ý nghĩ đến cái chết.

Bảng 1. Tỉ lệ bệnh nhân có khó khăn tâm lý

\begin{tabular}{llll}
\hline Nhóm bệnh & Tổng số & \multicolumn{2}{c}{ Bệnh nhân có khó khăn tâm lý } \\
\cline { 3 - 4 } & bệnh nhân & Số lượng & Tỉ lệ\% \\
\hline Cấp tính & 194 & 60 & $30,9^{(1)}$ \\
Mạn tính & 150 & 45 & $30,0^{(2)}$ \\
Ác tính & 56 & 25 & $44,6^{(3)}$ \\
Tính chung & 400 & 130 & 32,5 \\
p & $\mathrm{p}^{(1),(2)^{*}}>0,05 ; \mathrm{p}^{(1)(3)}<0,05$ & \\
\hline
\end{tabular}

Bảng 2. Những khó khăn tâm lý của bệnh nhân theo nhóm bệnh

\begin{tabular}{|c|c|c|c|c|c|c|c|c|}
\hline \multirow{2}{*}{$\begin{array}{l}\text { Nhóm bệnh } \\
\text { Khó khăn } \\
\text { tâm lý }\end{array}$} & \multicolumn{2}{|c|}{ Cấp tính } & \multicolumn{2}{|c|}{ Mạn tính } & \multicolumn{2}{|c|}{ Bệnh ác tính } & \multicolumn{2}{|c|}{ Tính chung } \\
\hline & $\begin{array}{l}\text { Số } \\
\text { lượng }\end{array}$ & $\begin{array}{l}\text { Tỉ lẹ } \\
\%\end{array}$ & $\begin{array}{l}\text { Số } \\
\text { lượng }\end{array}$ & $\begin{array}{l}\text { Tỉ lệ } \\
\%\end{array}$ & Số lượng & Tỉ lẹ\% & $\begin{array}{l}\text { Số } \\
\text { lượng }\end{array}$ & Tỉ lẹ\% \\
\hline Lo lắng & 33 & $55,0^{(1)}$ & 37 & $82,0^{(2)}$ & 20 & $80,0^{(3)}$ & 90 & 69,3 \\
\hline Sợ hãi & 25 & $41,7^{(4)}$ & 6 & $13,4^{(5)}$ & 3 & $12,0^{(6)}$ & 34 & 26,1 \\
\hline Buồn chán & 2 & 3,3 & 1 & 2,3 & 1 & 4,0 & 4 & 3,1 \\
\hline Nghĩ đến cái chết & 0 & 0 & 1 & 2,3 & 1 & 4,0 & 2 & 1,5 \\
\hline Tổng cộng & 60 & 100,0 & 45 & 100,0 & 25 & 100,0 & 130 & 100,0 \\
\hline $\mathrm{p}$ & \multicolumn{8}{|c|}{ 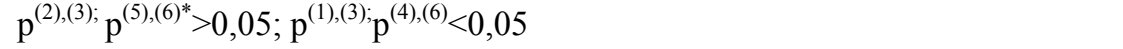 } \\
\hline
\end{tabular}


Bảng 3. Nhu cầu chia sẻ tâm lý của bệnh nhân

\begin{tabular}{|c|c|c|c|c|c|c|c|c|}
\hline \multirow{2}{*}{$\begin{array}{l}\text { Người chia sẻ } \\
\text { Nhóm } \\
\text { bệnh }\end{array}$} & \multicolumn{2}{|c|}{ Nhân viên y tế } & \multicolumn{2}{|c|}{ Người thân } & \multicolumn{2}{|c|}{ Đồng nghiệp } & \multicolumn{2}{|c|}{ Người khác } \\
\hline & $\begin{array}{l}\text { Số } \\
\text { lượng }\end{array}$ & Tỉ lẹ\% & $\begin{array}{l}\text { Số } \\
\text { lượng }\end{array}$ & Tỉlẹ\% & $\begin{array}{l}\text { Số } \\
\text { lượng }\end{array}$ & Tỉ lẹ\% & $\begin{array}{l}\text { Số } \\
\text { lượng }\end{array}$ & Tỉlẹ\% \\
\hline Cấp tính (194BN) & 82 & $42,2^{(I)}$ & 16 & 8,2 & 0 & 0 & 0 & 0 \\
\hline Mạn tính (150 BN) & 33 & $22,0^{(2)}$ & 10 & 6,7 & 1 & 0,6 & 1 & 0,6 \\
\hline Ác tính $(56 \mathrm{BN})$ & 7 & $12,5^{(3)}$ & 6 & 10,7 & 0 & 0 & 0 & 0 \\
\hline $\mathrm{p}$ & \multicolumn{8}{|c|}{$\mathrm{p}^{(1),(3)}<0,05 ; \mathrm{p}^{(2),(3)}>0,05$} \\
\hline
\end{tabular}

Kết quả nghiên cứu của chúng tôi cũng cho thấy tỉ lệ bệnh nhân tìm đến chia sẻ với nhân viên y tế chiếm tỉ lệ cao nhất, nhưng tỉ lệ này ở nhóm bệnh nhân mắc bệnh mạn tính và ác tính thấp hơn nhóm bệnh nhân mắc bệnh cấp tính (Bảng 3). Theo chúng tôi do bệnh nhân mắc các bệnh cấp tính đòi hỏi sự can thiệp tức thời các phương thức chữa trị do các nhân viên y tế đảm nhiệm nên bệnh nhân tìm đến với nhân viên y tế nhiều hơn, trong khi bệnh nhân mắc bệnh mạn tính do phải điều trị dài ngày, bệnh tiển triển chậm (hoặc có bệnh nhân đã biết trước căn bệnh ác tính của mình không điều trị được) nên ngoài việc chia sẻ với nhân viên y tế họ còn tìm đến chia sẻ với những người khác hoặc họ sống khép kín hơn.

Bảng 4. Nhu cầu chăm sóc toàn diện (bao gồm chăm sóc tinh thần) của bệnh nhân

\begin{tabular}{|c|c|c|c|c|c|c|}
\hline \multirow[b]{2}{*}{$\begin{array}{l}\text { Nhóm } \\
\text { bệnh }\end{array}$} & \multicolumn{2}{|c|}{ Thuốc đơn thuần } & \multicolumn{2}{|c|}{ Chăm sóc toàn diện } & \multicolumn{2}{|c|}{ Biện pháp khác } \\
\hline & $\begin{array}{c}\text { Số } \\
\text { lượng }\end{array}$ & $\begin{array}{c}\text { Ti lê } \\
\%\end{array}$ & Số lượng & $\begin{array}{l}\text { Tỉ lê } \\
\%\end{array}$ & $\begin{array}{c}\text { Số } \\
\text { lượng }\end{array}$ & $\begin{array}{c}\text { Tilệ } \\
\%\end{array}$ \\
\hline Cấp tính (194BN) & 168 & $86,5^{(1)}$ & 26 & $13,4^{(3)}$ & 0 & 0 \\
\hline Mạn tính (150 BN) & 90 & 60,0 & 40 & 26,7 & 20 & 13,3 \\
\hline Ác tính (56 BN) & 26 & $46,4^{(2)}$ & 23 & $41,0^{(4)}$ & 7 & 12,5 \\
\hline $\mathrm{p}$ & & & $p^{(1),(2) v}$ & $<0,05$ & & \\
\hline
\end{tabular}

Kết quả bảng cho thấy tỉ lệ tỉ lệ bệnh nhân có nhu cầu được chăm sóc toàn diện khá cao, tỉ lệ này bệnh nhân mắc bệnh ác tính có nhu cầu chăm sóc toàn diện cao hơn so với bệnh nhân cấp tính $(41,0 \%$ so với $13,4 \% ; \mathrm{p}<0,05)$ (Bảng 4), nhưng cũng còn rất nhiều bệnh nhân cho rằng chỉ cần điều trị thuốc đơn thuần, đặc biệt là nhóm bệnh nhân mắc bệnh cấp tính $(86,5 \%$ so với $46,4 \% ; \mathrm{p}<0,05)$. Chúng tôi thấy những bệnh nhân mắc bệnh mạn tính và ác tính có nhu cầu chăm sóc toàn diện cao hơn bệnh nhân cấp tính, phải chăng do quá trình điều trị kéo dài làm cho tâm lý bệnh nhân rất nặng nề và bệnh nhân cần có sự chia sẻ tâm lý cùng với hướng dẫn các kỹ thuật điều trị khác. Kết quả bảng cho thấy có trên $10,0 \%$ bệnh nhân mạn tính và ác tính ngoài việc sử dụng thuốc và chăm sóc tâm lý họ còn tìm đến những sự trợ giúp khác, mà phổ biến nhất là họ tìm đến với tâm linh. Hiện nay tại một số cơ sở điều trị bệnh nhân ung bướu có đề xuất liệu pháp 4T trong đó $\mathrm{T} 1$ là Tinh thần - tâm lý - tâm linh liệu pháp; T2 là Thực phẩm liệu pháp; T3 là Tập dưỡng sinh liệu pháp; T4 là Thuốc: Đông, Tây y (hóa trị, mổ, xạ trị). Trong đó T4 là do các bác sĩ thực hiện, 3T còn lại do chính bệnh nhân tự thực hiện, bác sĩ chỉ nhắc nhở, hướng dẫn.

Kết quả cho thấy $62,7 \%$ nhân viên y tế có quan tâm đến vấn đề chăm sóc tâm lý cho bệnh nhân, tỉ lệ này ở các bác sĩ cao hơn so với hộ sinh và điều dưỡng $(\mathrm{p}<0,05)$ (Bảng 5$)$, nhưng giữa nhóm hộ sinh và điều dưỡng viên thì tỉ lệ quan tâm đến tâm lý bệnh nhân là không khác biệt. 
Bảng 5. Thái độ của NVYT về chăm sóc tâm lý cho bệnh nhân

\begin{tabular}{lllll}
\hline Chuyên môn & Tổng số & \multicolumn{2}{c}{ Có quan tâm } & \multirow{2}{*}{$\mathrm{p}$} \\
\cline { 3 - 4 } & & Số lượng & Tỉ lệ $\%$ & \\
\hline Bác sĩ & 18 & 15 & $83,3^{(1)}$ & \multirow{2}{*}{$\mathrm{p}^{(1) \text { và(2)(3) }}<0,05 ; \mathrm{p}^{(2),(3)}>0,05$} \\
Y sĩ Sản, Hộ sinh & 58 & 30 & $51,7^{(2)}$ & \\
Điều dưỡng & 74 & 49 & $66,2^{(3)}$ & \\
Tính chung & 150 & 94 & 62,7 & \\
\hline
\end{tabular}

Bảng 6. Cách thức chăm sóc tâm lý cho bệnh nhân theo nghề nghiệp của NVYT

\begin{tabular}{lllll}
\hline \multirow{2}{*}{ Cách thức chăm sóc tâm lý } & \multicolumn{2}{l}{ Giải thích } & \multicolumn{3}{c}{ An ủi, động viên } \\
\cline { 2 - 5 } Chuyên môn & Số lượng & $\%$ & Số lượng & $\%$ \\
\hline Bác sĩ (18BS) & 12 & $66,7^{(1)}$ & 5 & $27,8^{(3)}$ \\
Y sĩ Sản, Hộ sinh (58 YS, HS) & 33 & 56,9 & 12 & 20,7 \\
Điều dưỡng viên (74ĐDV) & 42 & $56,7^{(2)}$ & 13 & $17,6^{(4)}$ \\
Tính chung (150 NVYT) & 87 & 58,0 & 30 & 20,0 \\
$\mathrm{p}$ & $\mathrm{p}^{(1)(2)} ; \mathrm{p}^{(3)(4)}<0,05$ & & \\
\hline
\end{tabular}

Bảng 6 cho thấy $58,0 \%$ nhân viên chỉ biết giải thích bệnh tật và $20,0 \%$ nhân viên an ủi động viên bệnh nhân mà không biết làm gì khác. Tỉ lệ bác sĩ giải thích và động viên bệnh nhân cao hơn so với điều dưỡng viên $(\mathrm{p}<0,05)$ (Bảng 6), tuy nhiên tỉ lệ này ở nhóm hộ sinh và điều dưỡng là không khác biệt. Chúng tôi thấy điều này cũng hoàn toàn phù hợp vì ngay trong hướng dẫn của Bộ $Y$ tế về tăng cường chăm sóc bệnh nhân toàn diện cũng chỉ có một điều rất ngắn gọn về chăm sóc tinh thần cho bệnh nhân
[5], nội dung chăm sóc toàn diện của Bộ Y tế cũng chỉ nhấn mạnh đến tỉ lệ điều dưỡng viên/bác sĩ, đảm bảo chế độ dinh dưỡng, cung cấp nước uống mà không quan tâm đển sức khỏe tinh thần của bệnh nhân. Hơn nữa, kiến thức của nhân viên y tế tại các cơ sở y tế về tâm lý y học rất hạn chế, họ chỉ được học rất ít về tâm lý bệnh nhân trong chương trình đào tạo, nên họ không biết làm gì hơn là giải thích và động viên mặc dù những vấn đề tâm lý của bệnh nhân là rất đa dạng và phức tạp [7].

Bảng 7. Thời gian tiếp xúc hàng ngày của NVYT với bệnh nhân

\begin{tabular}{lcccccc}
\hline \multirow{2}{*}{ Thời gian } & \multicolumn{2}{c}{ Dưới 10 phút } & \multicolumn{2}{c}{ 10-30 phút } & \multicolumn{2}{c}{ Trên 30 phút } \\
\cline { 2 - 7 } Chuyên môn & $\begin{array}{c}\text { Số } \\
\text { lượng }\end{array}$ & Tỉ lẹ \% & $\begin{array}{c}\text { Số } \\
\text { lượng }\end{array}$ & Tỉ lệ\% & $\begin{array}{c}\text { Số } \\
\text { lượng }\end{array}$ & Tì lệ\% \\
\hline Bác sĩ (18) & 13 & 72,2 & 5 & 27,7 & 1 & 5,5 \\
Y sĩ Sản, Hộ sinh (58) & 7 & 12,0 & 14 & 24,1 & 37 & 63,7 \\
Điều dưỡng viên (74) & 11 & 14,9 & 21 & 28,3 & 32 & 43,2 \\
\hline
\end{tabular}

Thời gian tiếp xúc hàng ngày với bệnh nhân của NVYT cũng khác nhau, đáng chú ý là tỉ lệ bác sĩ đành thời gian trung bình cho mỗi bệnh nhân dưới 10 phút/bệnh nhân/ngày rất cao $(72,2 \%)$, thông thường các bác sĩ chỉ khám bệnh buổi sáng (đi buồng) hàng ngày, sau khi khám bệnh bác sĩ ra y lệnh, thực hiện y lệnh là công việc của điều dưỡng viên (Bảng 7). Tại Mỹ theo số liệu nghiên cứu Abigail Zuger cho thấy bác sĩ dành thời gian cho máy tính nhiều hơn cho bệnh nhân, họ chỉ dành 8 phút/bệnh nhân và chỉ có $12 \%$ thời gian làm việc bên 
giường bệnh [8]. Johnna I Wetbrook và $\mathrm{CS}$ nghiên cứu thời gian làm việc của 57 điều dưỡng viên tại Australia thấy họ chỉ dành $37 \%$ thời gian hàng ngày cho bệnh nhân và qua thời gian hành nghề thì thời gian dành cho truyền thông và tư vấn ngày càng giảm đi $(24 \%$ xuống còn $19,2 \%$ ) [9]. Tiến hành nghiên cứu định tính cho thấy có nhiều lý do làm cho công tác chăm sóc tâm lý cho bệnh nhân bị "bỏ quên", nhưng chủ yếu là do nhân viên y tế chưa ý thức hết được tầm quan trọng của chăm sóc tâm lý, bên cạnh dó do áp lực công việc, thời gian dành cho bệnh nhân không nhiều, nhân viên y tế lại thiếu kiến thức và kỹ năng nên làm cho việc chăm sóc tâm lý bệnh nhân càng thêm khó khăn. Tại Việt Nam, việc chăm sóc tâm lý cho người bệnh là một mảng hoàn toàn thiếu trong các cơ sở $\mathrm{y}$ tế. Gần đây nhất, trong chương trình đào tạo ngành $\mathrm{Y}$ đa khoa và $\mathrm{Cử}$ nhân điều dưỡng của Bộ Giáo dục và Đào tạo môn Tâm lý Y học và Đạo đức $\mathrm{Y}$ học cũng chỉ giới thiệu khái niệm (45 tiết lý thuyết) về Tâm lý y học và đạo đức nghề nghiệp [10]. Do vậy, kiến thức và kỹ năng thực hành của nhân viên y tế chưa đáp ứng được việc chăm sóc tâm lý cho bệnh nhân, nếu có quan tâm đến thì cũng chỉ biết động viên, giải thích bệnh tình của bệnh nhân cho họ biết mà không giải quyết hết được mọi vấn đề liên quan đến người bệnh.

\section{Kết luận}

Tỉ lệ bệnh nhân có khó khăn tâm lý khá cao, nhân viên y tế vẫn là đối tượng được bệnh nhân và người thân của họ tìm đển chia sẻ nhiều nhất, nhưng tỉ lệ nhân viên y tế ý thức được tầm quan trọng của chăm sóc tâm lý chưa cao, nếu có quan tâm thì họ cũng chỉ biết giải thích hoặc động viên an ủi người bệnh. Do vậy, rất cần phải có đội ngũ nhân viên chăm sóc tâm lý cho bệnh nhân một cách chuyên nghiệp, được đào tạo chính quy, bài bản. Đội ngũ này tốt nhất là các chuyên gia Tâm lý học lâm sàng được đào tạo tại các đơn vị hiện đang đào tạo ngành Tâm lý của Việt Nam.

\section{Lời cảm ơn}

Chúng tôi trân trọng cảm ơn sự tài trợ của Đại học Quốc Gia Hà Nội cho đề tài mã số QG.12.26 để thực hiện nghiên cứu này.

\section{Tài liệu tham khảo}

[1] WHO, Declaration of Alma-Ata, International Conference on Primary Health Care, Alma-Ata, USSR, 1978, 6-12

[2] WHO, Global status report on communicable diseases 2010.

[3] WHO, Highlights global underinvestment in mental health care, 2011.

[4] WHO, Integrating mental health into primary care: a global perspective", 2008.

[5] Bộ Y tế, Hướng dẫn công tác điều dưỡng chăm sóc người bệnh trong $\mathrm{BV}, 2011$.

[6] Bộ Y tế, Đề án Phát triển nghề Công tác xã hội trong ngành Y tế giai đoạn 2011-2020, 2011.

[7] Nguyễn Văn Ngân, Nguyễn Văn Nhận, Nguyễn Sinh Phúc, Tâm thần học đại cương và tâm lý y học, Học viện Quân y, (1998), 173-199.

[8] Abigail Zuger, Work Habits of the 21stCentury Intern, J Gen Intern Med, (2013).

[9] Johanna I Westbrook, Christine Duffield, How much time do nurses have for patients? a longitudinal study quantifying hospital nurses' patterns of task time distribution and interactions with health professionals, BMC Health Serv Res,11, (2011), 319.

[10] Bộ Giáo dục và Đào tạo (2012), Thông tư số 01/2012/TT - BGDĐT ngày 13 tháng 01 năm 2012 của Bộ trưởng Bộ GD\&ĐT về Khung chương trình Giáo dục đại học. 


\title{
Reseach on Demand for Training Bachelor of Clinical Psychology for Health Facilities
}

\author{
Pham Trung Kien ${ }^{1}$, Tran Thu Huong ${ }^{2}$ \\ ${ }^{1}$ VNU Hanoi School of Medicine and Pharmacy, 144 Xuan Thuy, Cau Giay, Hanoi, Vietnam \\ ${ }^{2}$ VNU University of Social Sciences and Humanities, \\ 336 Nguyen Trai, Thanh Xuan, Hanoi, Vietnam
}

\begin{abstract}
Research on the psychological difficulties and need of mental care for patients and their relatives in the hospital are basic to determine demand for training and using staffs for psychological care. The obtained results found that $32.5 \%$ of patients in the hospital had psychological difficulties; percentage of patients who need to share with the medical staff was $42.0 \%$; there had $41.0 \%$ of patients in need of comprehensive care; $51.5 \%$ of patients relatives needed medical staffs to care for the patients; the rate of medical staffs interested in psychological care for patients was $62.7 \%$ but their main skills were of interpretation and encouragement. The leading boards of the surveyed hospitals strongly supported to need teams of experts to care psychologically for patients, in which bachelors of clinical psychology are the most suitable in this issue.
\end{abstract}

Keywords: Psychological difficulties; Psychology patients; Clinical Psychology. 